\title{
Rainfall-induced Failures of Residual Soil Slopes with Spatial Variability of Hydraulic Conductivity
}

\author{
Muhammad Suradi ${ }^{1, a}$ \\ ${ }^{1}$ Civil Engineering Department, State Polytechnic of Ujung Pandang, \\ Jl. P. Kemerdekaan Km 10, Makassar, 90245, Indonesia \\ amsuradi@poliupg.ac.id; smr0221@yahoo.com
}

\begin{abstract}
The aim of this paper was to examine the effect of spatial variability of hydraulic conductivity, commonly existing in nature, on rainfall-induced failures of residual soil slopes. Parametric study was carried out at typically residual soil slopes with two distinctively different types of hydraulic conductivity, high $\left(k_{s}=10^{-4} \mathrm{~m} / \mathrm{s}\right)$ and low $\left(k_{s}=10^{-6} \mathrm{~m} / \mathrm{s}\right)$ conductivity, in Singapore. Finite element method was applied in this slope stability analysis using commercial SVFlux and SVSlope software in a couple manner. Rainfall intensity was varied as a fraction of the hydraulic conductivity. As a result, greater spatial variability of saturated hydraulic conductivity affects more noticeably the instability of both high and low-conductivity soil slopes exposed to high-rainfall intensity (I > $0.05 \mathbf{k}_{\mathrm{s}}$ for high-conductivity slopes and $I>1 k_{s}$ for low- conductivity slopes). However, there was a negligible effect of spatial variability of hydraulic conductivity on the instability of slopes subjected to low-rainfall intensity, even this spatial variability tended to slightly increase the stability of high-conductivity slopes.
\end{abstract}

Keywords - spatial variability; hydraulic conductivity; rainfallinduced failure; residual soil slope; finite element

\section{Introduction}

Rainfall-induced slope failures commonly occur around the world particularly during rainy season. These occurrences often result in serious impacts such as economic loss, infrastructure damages, environmental deterioration, and fatalities. Although vast number of studies [1, 2, 3, 4, 5, 6, 7, 8, 9] have indicated rainfall events as a primary cause of slope failures, soil properties also contributed to this slope failure mechanism such as different failure mechanisms typically taking place between in Hong Kong and Singapore. The slope failures in Hong Kong generally occur under short and intense rainfall (Brand et al., 1984) but typically very long and less intense rainfall induces the slope instability in Singapore [8, 10, 11].
These findings were attributed to dominantly sandy soils found in Hong Kong while usually clayey soils are observed in Singapore. From this observation, it is clear that besides rainfall events, hydraulic conductivity of soil also plays a key role in rainfall-induced failures of the slopes. Moreover, residual soil slopes have experienced a very long and severe weathering process, consequently these slopes are potentially susceptible to instability (Gidigasu, 1972).

Many researchers have studied the effect of hydraulic conductivity of soil on rainfall-induced slope failures but most of them, if not all, used deterministic method in performing their studies $[12,13,6,14,15]$. A single value of soil properties was applied in this method, in fact, the properties - particularly hydraulic conductivity of residual soil slopes - were greatly spatially variable $[16,17]$. This variability could create great uncertainty of rainwater infiltration [18] and subsequently generate pore-water pressure that might have significant effect on the instability of slopes compared to a single value of the soil property used in the deterministic analysis. This study examined the effect of spatial variability of hydraulic conductivity on rainfall-induced slope failures. The commercial SVFlux coupled with SVSlope software [19] was used to carry out this slope stability analysis.

This analysis was performed in two steps i.e., seepage and slope stability analyses. Seepage analysis was carried out to compute pore-water pressure, and then this pore-water pressure was used as input parameters to calculate the factor of safety in assessing slope stability. 
The water flow governing equation was used to solve a transient and two-dimensional seepage analysis as written below:

$m_{w}{ }^{2} \gamma_{w} \frac{\partial h_{w}}{\partial t}=\frac{\partial}{\partial x}\left(-k_{w x} \frac{\partial h_{w}}{\partial x}\right)+\frac{\partial}{\partial y}\left(-k_{w y} \frac{\partial h_{w}}{\partial y}\right)+q$

The variables associated with this equation are defined as follows: $\mathrm{m}_{\mathrm{w}}{ }^{2}=$ slope of SWCC; $\gamma_{\mathrm{w}}=$ unit weight of water; $\mathrm{h}_{\mathrm{w}}=$ hydraulic head (total head); $\mathrm{t}=$ time; $\mathrm{k}_{\mathrm{wx}}=$ hydraulic conductivity with respect to water as a function of matric suction in the $\mathrm{x}$-direction; $\mathrm{k}_{\mathrm{wy}}=$ hydraulic conductivity with respect to water as a function of matric suction in the $\mathrm{y}$-direction; and $\mathrm{q}=$ applied flux at the boundary.

Parameters of hydraulic properties such as hydraulic conductivity and soil water characteristic curve (SWCC) were used as input parameters in the seepage analysis. Spatial variability of hydraulic conductivity was randomly varied in this analysis while the SWCC parameters were taken as a single value to investigate the effect of spatial variability of hydraulic conductivity on the instability of slope exposed to rainfall. A series of different coefficients of variation of hydraulic conductivity were applied to account for the variation of spatial variability at the slope.

The shear strength equation for unsaturated soils [20] was used to involve contribution of matric suction in slope stability analysis as written below:

$$
\tau=\mathrm{c}^{\prime}+\left(\sigma_{\mathrm{n}}-\mathrm{u}_{\mathrm{w}}\right) \tan \phi^{\prime}+\left(\mathrm{u}_{\mathrm{a}}-\mathrm{u}_{\mathrm{w}}\right) \tan \phi^{\mathrm{b}}
$$

The variables associated with this equation are defined as follows: $\tau=$ shear strength of unsaturated soil; $\mathrm{c}^{\prime}=$ effective cohesion; $\left(\sigma_{\mathrm{n}}-\mathrm{u}_{\mathrm{w}}\right)=$ effective normal stress; $\left(\mathrm{u}_{\mathrm{a}}-\mathrm{u}_{\mathrm{w}}\right)=$ matric suction; $\mathrm{u}_{\mathrm{w}}=$ pore-water pressure; $\mathrm{u}_{\mathrm{a}}$ $=$ pore-air pressure; $\phi^{\prime}=$ effective angle of internal friction angle; and $\phi^{\mathrm{b}}=$ angle indicating the rate of increase in shear strength relative to the matric suction. Each parameter used in this analysis was also taken as a single value because only hydraulic conductivity was varied. Janbu simplified method of analysis was used to consider non-circular or uncertainty of slope failure shape due to spatial variability of hydraulic conductivity applied in this analysis. Efforts and time required to perform this analysis were much less than rigorous methods but the result of analysis is relatively accurate [21].

\section{Research Methodology}

Parametric study was conducted to investigate the effect of spatial variability of hydraulic conductivity on rainfall-induced slope failures. Two distinctively different types of slope soils, high $\left(\mathrm{k}_{\mathrm{s}}=10^{-4} \mathrm{~m} / \mathrm{s}=0.36\right.$ $\mathrm{m} / \mathrm{hr})$ and low $\left(\mathrm{k}_{\mathrm{s}}=10^{-6} \mathrm{~m} / \mathrm{s}=0.0036 \mathrm{~m} / \mathrm{hr}\right)$ saturated hydraulic conductivity, were observed in this study. Rainfall intensity (I) was varied as a fraction or multiplication of the hydraulic conductivity such as $1 \mathrm{k}_{\mathrm{s}}$, $0.5 \mathrm{k}_{\mathrm{s}}, 0.1 \mathrm{k}_{\mathrm{s}}, 0.05 \mathrm{k}_{\mathrm{s}}, 0.01 \mathrm{k}_{\mathrm{s}}$, and $0.005 \mathrm{k}_{\mathrm{s}}$ for the high conductivity and $10 \mathrm{k}_{\mathrm{s}}, 4 \mathrm{k}_{\mathrm{s}}, 0.25 \mathrm{k}_{\mathrm{s}}$, and $0.1 \mathrm{k}_{\mathrm{s}}$ for the low conductivity. To examine the effect of spatial variability, coefficients of variation $(\mathrm{CV})$ of the hydraulic conductivity were widely varied from $0 \%$ to $500 \%$ for each case as shown in Table 1 . This wide variation was expected to produce significant effect on the instability of slopes.

Table 1. Parameters Used in the Parametric Study

\begin{tabular}{|c|c|c|c|c|}
\hline \multirow{2}{*}{$\begin{array}{l}\text { Case } \\
\text { Study }\end{array}$} & \multirow{2}{*}{ Types of Soil } & \multicolumn{3}{|c|}{ Variation of Parameters } \\
\hline & & $\mathrm{k}_{\mathrm{s}}(\mathrm{m} / \mathrm{hr})$ & $\mathrm{I}(\mathrm{m} / \mathrm{hr})$ & CV (\%) \\
\hline \multirow{4}{*}{1} & \multirow{4}{*}{$\begin{array}{c}\text { High } \\
\text { Conductivity }\end{array}$} & \multirow{4}{*}{0.36} & $1.5 \mathrm{k}_{\mathrm{s}}$ & $0,10,40,100,500$ \\
\hline & & & $1 \mathrm{k}_{\mathrm{s}}$ & $0,10,40,100,500$ \\
\hline & & & $0.1 \mathrm{k}_{\mathrm{s}}$ & $0,10,40,100,500$ \\
\hline & & & $0.01 \mathrm{k}_{\mathrm{s}}$ & $0,10,40,100,500$ \\
\hline \multirow{3}{*}{2} & \multirow{3}{*}{$\begin{array}{c}\text { Low } \\
\text { Conductivity }\end{array}$} & \multirow{3}{*}{0.0036} & $4 \mathrm{k}_{\mathrm{s}}$ & $0,10,40,100,500$ \\
\hline & & & $0.5 \mathrm{k}_{\mathrm{s}}$ & $0,10,40,100,500$ \\
\hline & & & $0.25 \mathrm{k}_{\mathrm{s}}$ & $0,10,40,100,500$ \\
\hline
\end{tabular}

Finite element method was applied to analyze the effect of spatial variability of hydraulic conductivity on rainfall-induced slope failures using commercial Soil Vision software package particularly SVFlux and SVSlope. To perform easily both analyses, the SVFlux and SVSlope were used in a coupled manner. In this software package, the analysis of seepage generated by rainfall was performed using the SVFlux and result of this analysis was automatically transferred as input parameters for the next step, slope stability analysis using the SVSlope.

Analysis modeling was set into two steps: seepage and slope stability analyses. A typical residual soil slope in Singapore was taken as a case example in this study [15] with geometry and boundary conditions shown in Figure 1. First, seepage analysis model was set as a twodimensional (2D) transient analysis with metric units 
(length in meter and time in hour). To observe slope stability recovery after the stop of rainfall, a sufficiently long observation period was taken with respect to rainfall duration. In this study, we applied $24 \mathrm{hrs}$ rainfall, thus $240 \mathrm{hrs}$ observation period was used to allow sufficient time to recover the slope stability indicated by the factor of safety. Mixed (mass conservative) transient formulation was used to solve seepage analysis and spatial variability method was selected to examine the effect of various spatial variabilities of hydraulic conductivity at the residual soil slopes [19]. Geometry and groundwater table depth as shown in Figure 1 only determine initial safety of factor for a slope as indicated by [10] so these parameters were taken as constant values, which represent typical properties of residual soil slopes in Singapore i.e., $15 \mathrm{~m}$ in height, $30^{\circ}$ in angle, $2 \mathrm{~m}$ in water table below the slope toe. No maximum matric suction was applied due to a relatively thin zone of unsaturated soil at the slope. Three types of boundary conditions were applied as follows: climate (rainfall intensity) along ground surface to allow rainwater infiltration, head expression at the left and right sides below groundwater table to allow free-flow through these boundaries. Zero flux was applied at the left and right sides above groundwater table and at the bottom of the slope to prevent flow through these boundaries. Constant rainfall intensity was applied in each case of study. Two types of soil properties were used as input parameters, hydraulic and shear strength properties. Amongst these soil properties, only hydraulic conductivity was varied as shown in Table 1 to ensure that the change in the slope stability is solely caused by the change of pore-water pressure in the soil. The remaining parameters were taken as constant values, for instance: soil water characteristic curve (SWCC) parameters a indicating air-entry value as well as $n$ and $\mathrm{m}$ indicating slope of the SWCC and residual water content of the soil respectively. The typical SWCC parameters were used in this analysis such as $a=10 \mathrm{kPa}$, $\mathrm{n}=1$, and $\mathrm{m}=1$ for high conductivity slopes and $\mathrm{a}=500$ $\mathrm{kPa}, \mathrm{n}=1$, and $\mathrm{m}=1$ for low conductivity slopes.

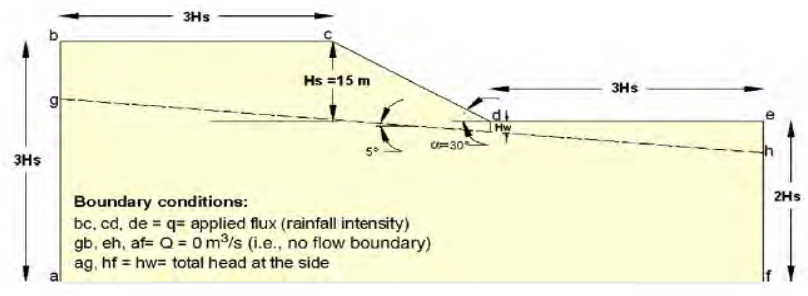

Figure 1. Geometry and Boundary Conditions of Residual Soil Slopes

Second, the slope stability analysis was set by selecting a possible shape of slip surface, search method of the slip surface, and calculation method associated with soil properties of the slope and method of analysis. In this case, non-circular slip surface, dynamic programming of the search method, and Janbu Simplified calculation method were selected. Shear strength parameters were also used as constant values such as: effective cohesion $\mathrm{c}^{\prime}=10 \mathrm{kPa}$, effective angle of internal friction $\phi^{\prime}=26^{\circ}$, rate of increase in shear strength generated by matric suction $\phi^{\mathrm{b}}=26^{\circ}$, and unit weight of soil, $\gamma=20 \mathrm{kN} / \mathrm{m}^{3}$. Complete analysis model in spatial variability of hydraulic conductivity is illustrated in Figure 2.

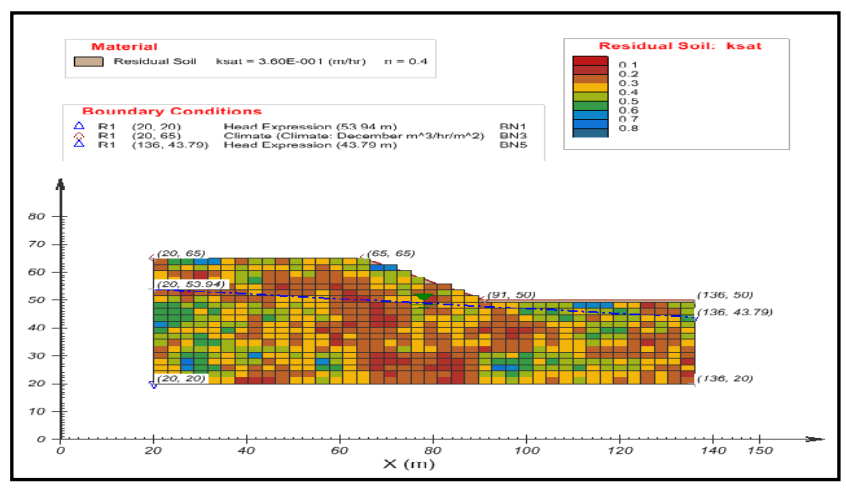

Figure 2. Analysis Model of Slope Stability with Spatial Variability of Hydraulic Conductivity

\section{Results and Discussion}

The results were presented based on number of cases as shown in Table 1. Generally this analysis showed similar results with those from the analysis performed by Rahimi et al. (2010). Slope stability indicated by factor of safety drastically decreased when the slope was subjected to high intensity of rainfall associated with hydraulic conductivity of the slope soil ( $>0.5 \mathrm{k}_{\mathrm{s}}$ ). Even the slope failure occurred several hours after the rainfall 
started, then this slope quickly recovered once it stopped. The higher the rainfall intensity, the faster slope failures occurred as shown in Figures 3a, 3b, 5a, and 5b. On the other hand, slope stability slowly decreased when the slope was subjected to low intensity of rainfall, then it gradually recovered since the rainfall stopped as shown in Figures 3d, 3e, 5c, and 5d. These phenomena indicated that rainfall intensity in conformity with soil hydraulic conductivity played an important role in determining water infiltration into the slope subsurface that subsequently affects the slope instability. Applied rainfall intensity, which approximately equals to hydraulic conductivity, produced great effect on slope instability because all rainwater could totally infiltrate into the slope. This infiltration generated significant pore-water pressure and thus considerably reduced shear strength that could instantly lead to slope failures.
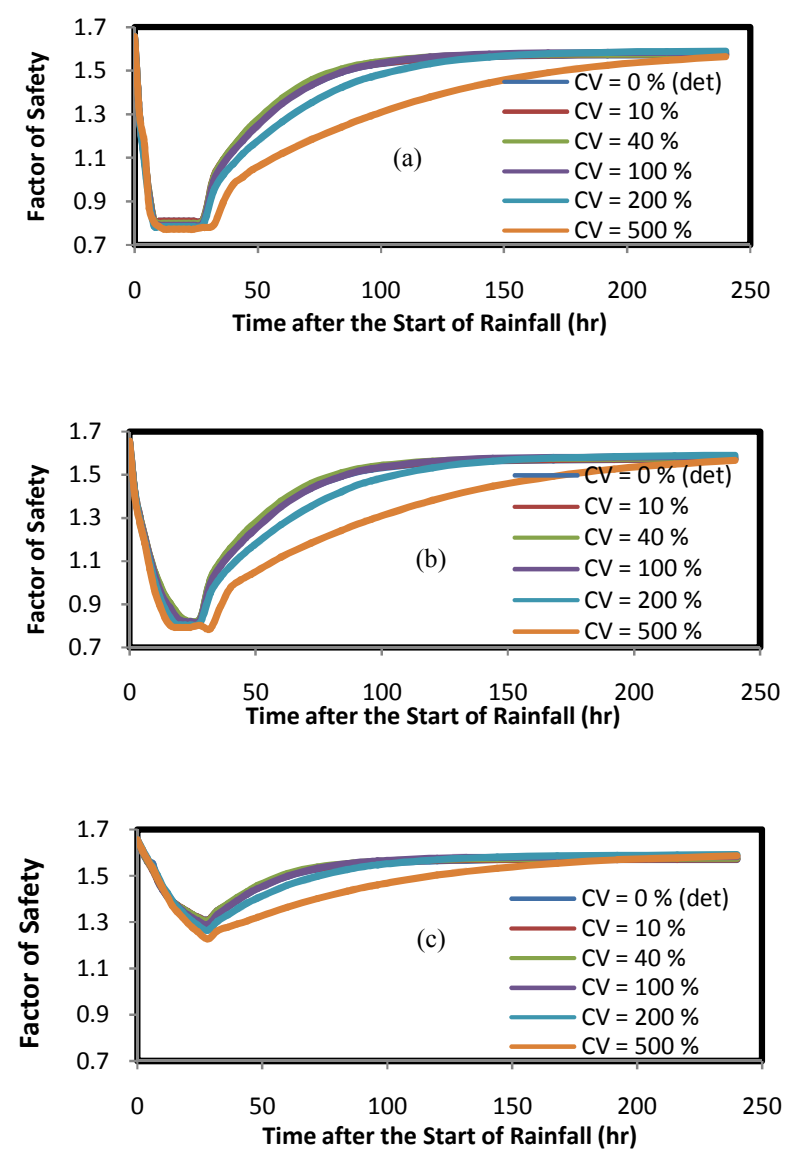
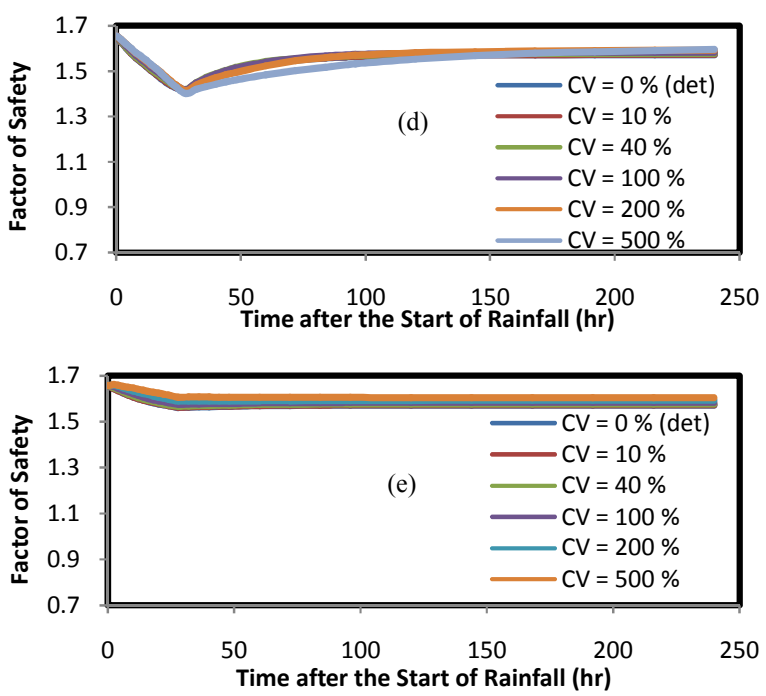

Figure 3. Factor of Safety of High-conductivity Slope $\left(\mathrm{k}_{\mathrm{s}}=0.36\right.$ $\mathrm{m} / \mathrm{hr}$ ) with Various Spatial Variabilities of Hydraulic Conductivity Subjected to Different Rainfall Intensities (I): (a) $\mathrm{I}=1 \mathrm{k}_{\mathrm{s}}$; (b) $\mathrm{I}=0.5 \mathrm{k}_{\mathrm{s}}$; (c) $\mathrm{I}=0.1 \mathrm{k}_{\mathrm{s}}$; (d) $\mathrm{I}=0.05 \mathrm{k}_{\mathrm{s}}$; (e) $\mathrm{I}=$ $0.01 \mathrm{k}_{\mathrm{s}}$

In particular, spatial variability of hydraulic conductivity noticeably affected rainfall-induced failures of both high and low-conductivity slopes when the slopes were subjected to sufficiently intense rainfall. This rainfall intensity was found to be higher than 0.05 $\mathrm{k}_{\mathrm{s}}$ for the high- conductivity slope and higher than $1 \mathrm{k}_{\mathrm{s}}$ for the low-conductivity slope to produce noticeable effect of the spatial variability on the instability of the slopes. This effect was only significant if spatial variability of hydraulic conductivity was large enough $(\mathrm{CV} \geq 100 \%)$ as shown in Figures 3a, 3b, 3c, 5a, and $5 \mathrm{~b}$. The higher the spatial variability of hydraulic conductivity, the lower minimum safety factors of slope were triggered by rainfall as shown in Figures 4 and 6 . Then, the factors of safety resulting from the higher spatial variability recovered much more slowly since rainfall stopped and eventually converged long after the cessation of rainfall for the high- conductivity slope but tended to diverge since rainfall ceased for the lowconductivity slope. However, there were negligible effects of spatial variability of hydraulic conductivity on slope stability when the slope was subjected to lowrainfall intensity i.e.: I $<0.05 \mathrm{k}_{\mathrm{s}}$ for high- conductivity slopes as shown in Figures $3 \mathrm{e}$ and 4 and $\mathrm{I}<1 \mathrm{k}_{\mathrm{s}}$ for lowconductivity slopes as shown in Figures 5c, 5d, and 6. 
Even spatial variability of hydraulic conductivity tended to increase stability of the high-conductivity slope.

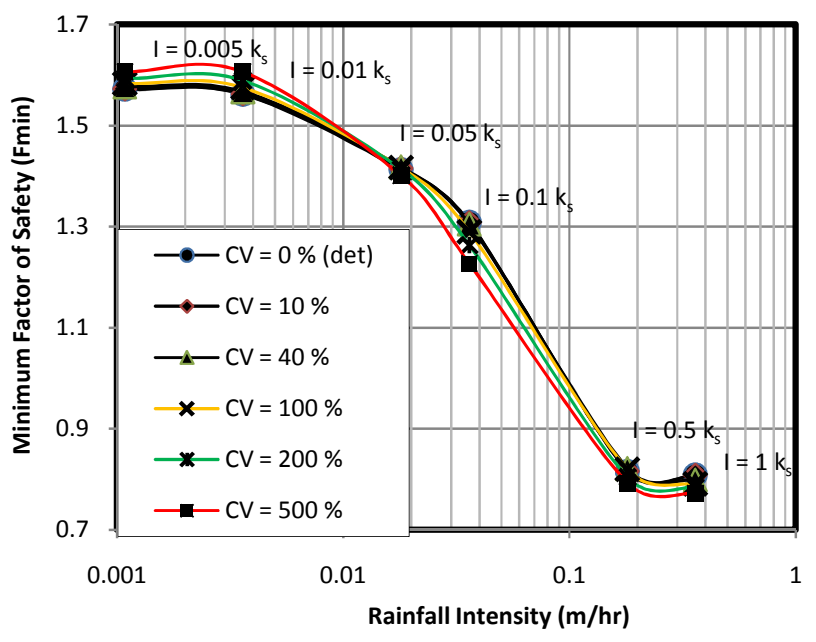

Note: $\mathrm{k}_{\mathrm{s}}=10^{-4} \mathrm{~m} / \mathrm{s}=0.36 \mathrm{~m} / \mathrm{hr}$ (saturated hydraulic conductivity)

Figure 4. Minimum Factor of Safety of High-conductivity Slope with Various Spatial Variabilities of Hydraulic Conductivity subjected to Different Rainfall Intensities

The occurrences above can be attributed to rainwater flow discontinuity created by the spatial variability of hydraulic conductivity, which further generates high pore-water pressure due to great preferential flow imposed by high-rainfall intensity. In contrast, this spatial variability reduces rainwater infiltration into slopes when these slopes were subjected to low-rainfall intensity and therefore reduces pore-water pressure, which subsequently increases stability of the slopes.

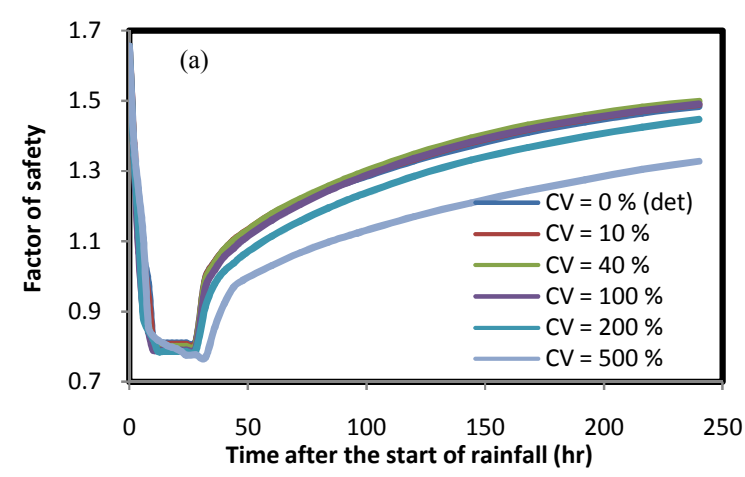

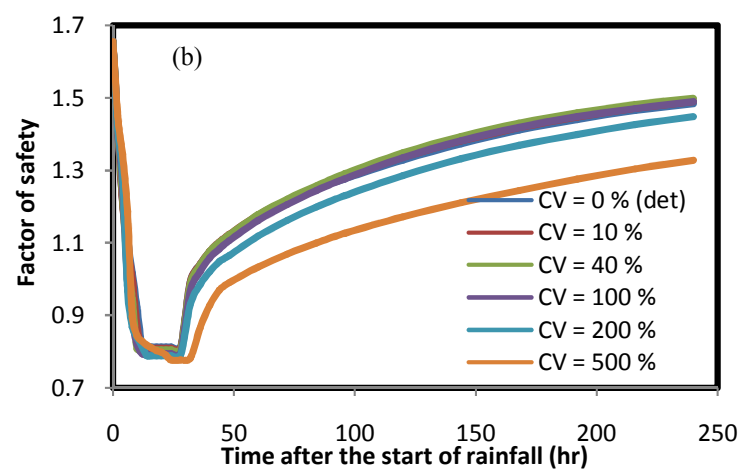
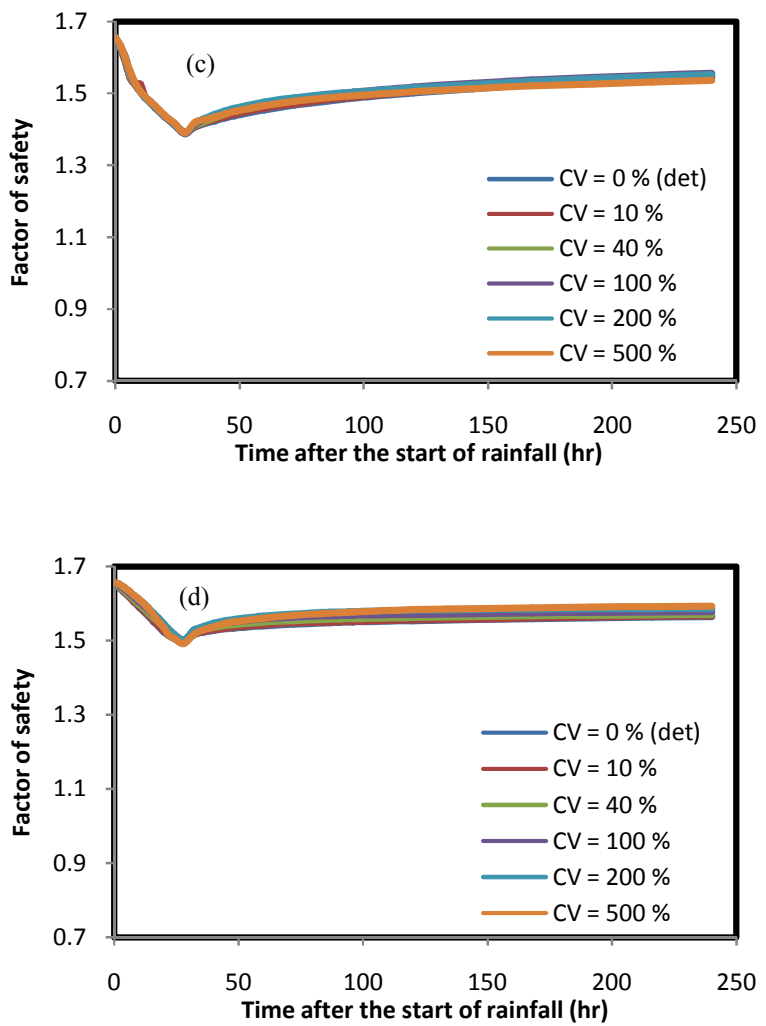

Figure 5. Factor of Safety of Low-conductivity Slopes $\left(\mathrm{k}_{\mathrm{s}}=0.0036 \mathrm{~m} / \mathrm{hr}\right)$ with Various Spatial Variabilities of Hydraulic Conductivity subjected to Different Rainfall Intensities (I): (a) I $=10 \mathrm{k}_{\mathrm{s}}$; (b) $\mathrm{I}=4 \mathrm{k}_{\mathrm{s}}$; (c) $\mathrm{I}=0.25 \mathrm{k}_{\mathrm{s}}$; (d) $\mathrm{I}=0.1 \mathrm{k}_{\mathrm{s}}$ 


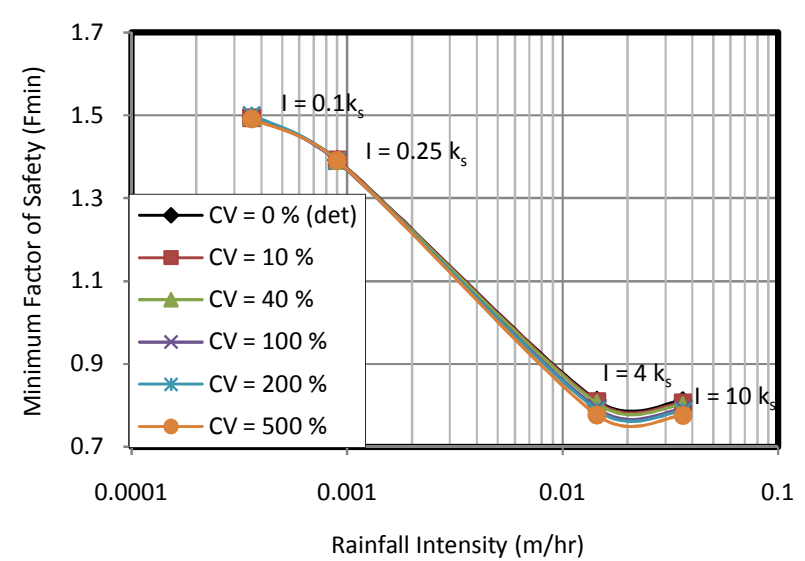

Note : $\mathrm{k}_{\mathrm{s}}=10^{-6} \mathrm{~m} / \mathrm{s}=0.0036 \mathrm{~m} / \mathrm{hr}$ (saturated hydraulic conductivity)

Figure 6. Minimum Factor of Safety of Low-conductivity Slopes with Various Spatial Variabilities of Hydraulic Conductivity subjected to Different Rainfall Intensities

\section{Conclusion}

This study revealed that high spatial variability $(\mathrm{CV} \geq$ $100 \%)$ of hydraulic conductivity, caused meaningful effect on the instability of rainfall-induced slope only if the slopes were subjected to high-rainfall intensity with regard to the hydraulic conductivity. The spatial variability created discontinuity of rainwater infiltration which subsequently generated pore-water pressure. This pore-water pressure further caused the slope instability. Therefore, the higher the spatial variability of hydraulic conductivity, the lower factors of safety were resulted in both high and low-conductivity slopes exposed to the high intensity of rainfall. On the other hand, low intensity of rainfall resulted in negligible effect on the rainfall-induced failures of residual soil slopes with spatial variability of hydraulic conductivity due to insufficient amount of rainwater infiltration.

\section{Acknowledgement}

Valuable comments on the manuscript by Andy Fourie of the UWA Professor are greatfully acknowledged. The assistance of Robert Thode of the Soil Vision staff is also appreciated.

\section{References}

[1] S.W.C. Au, "Rain-induced slope instability in Hong Kong," Engineering Geology, vol. 51, pp. 1-36, 1998.

[2] E.W. Brand, A. Premchitt, H.B. Phillipson, "Relationship between rainfall and landslide in Hong Kong," Proc. $4^{\text {th }}$ International Simposium on Landslides, Toronto, pp. 377-384, 1984.

[3] R.J. Eyles, "Slip-triggering rainfall in Wellington City, New Zealand," New Zealand Journal of Science, vol. 22, pp. 117$121,1979$.

[4] A.B. Fourie, " Predicting rainfall-induced slope instability," Proceedings of the Institution of Civil Engineers, Geotechnical Engineering, vol.119 (4), pp. 211-218, 1996.

[5] M. Fukuoka, "Landslides associated with rainfall," Geotechnical Engineering, Journal of Southeast Asian Geotechnical Society, vol. 11, pp. 1-29, 1980.

[6] P. Lumb, “ Slope failure in Hong Kong,” Q. J. Engineering Geology, vol. 8, 31-65, 1975.

[7] D. Pradel, G. Raad, "Effect of permeability on surficial stability of homogeneous slopes," Journal of Geotechnical Engineering, vol. 119(2), pp. 315-352, 1993.

[8] H. Rahardjo, T.T. Lee, E.C. Leong, R.B. Rezaur, "Response of a residual soil slope to rainfall," Can. Geotechnical Journal, vol. 42(2), pp. 340-351, 2005.

[9] I. Tsaparas, H. Rahardjo, D.G. Toll, E.C. Leong, "Controlling parameters for rainfall-induced landslides," Comput. Geotech., vol. 29(1), pp. 1-27, 2002.

[10] H. Rahardjo, T.T. Lee, T.H. Ong, E.C. Leong, R.B. Rezaur, "Factors controlling instability of homogeneous soil slopes under rainfall loading," J. Geotech. Geoenviron. Enggineering, vol. 133(12), pp. 1532-1543, $2007 \mathrm{~b}$.

[11] D.G. Toll, H. Rahardjo, E.C. Leong, "Landslides in Singapore," Proc. $2^{\text {nd }}$ Int. Conference on Landslides, Slope Stability, and the Safety of Infra-Structure, Singapore: CI-Premier Pte Ltd., 1999, pp. 269-276.

[12] P.J. Finlay, R. Fell, P.K. Maguire, "The relationship between the probability of landslide occurrence and rainfall," Can. Geotech. Journal, vol. 34, pp. 811-824, 1997.

[13] A. Hansen, "Engineering geomorphology: the application of an evolutionary model of Hong Kong's terrain," Z. Geomorphol. Suppl., vol. 51, pp. 39-50, 1984.

[14] J. Premchitt, "Salient aspects of Landslides in Hong Kong," Proc. $9^{\text {th }}$ Asian Regional Conference on Soil Mechanics and Foundation Engineering, Bangkok, Thailand, vol. 2, pp. 497$502,1991$.

[15] A. Rahimi, H. Rahardjo, E.C. Leong, "Effect of hydraulic properties of soil on rainfall-induced slope failure," Engineering Geology, vol. 114, pp. 135-143, 2010.

[16] S. Maail, B.B.K. Huat, S. Jamaludin, “ Index, engineering properties and classification of tropical residual soils," Taylor \& Francis Group, 2004, ISBN 905809660 2, pp. 376-455.

[17] L.D. Wesley, Geotechnical Engineering in Residual Soils, New Jersey: John Wiley \& Sons, 2010.

[18] A. Schneider, T. Baumgartl, D. Doley, D. Mulligan, "Evaluation of the heterogeneity of constructed landforms for rehabilitation using lysimeters," Vadose Zone Journal, vol. 9, pp. 898-909, 2010. 
[19] M. Fredlund, T. Feng, R. Thode, SVSlope: 2D Slope Stability Modeling Software, Tutorial Manual, Saskatchewan, Canada: Soil Vision System Ltd., 2008.

[20] D.G. Fredlund, N.R. Morgestern, R.A. Widger, "The shear strength of unsaturated soils," Canadian Geotechnical Journal, vol. 15(3), pp. 313-321, 1978 .
[21] D.G. Fredlund, J. Krahn, "Comparison of slope stability methods of analysis," Canadian Geotechnical Journal, vol. 14(3), pp. 429-439, 1977. 